\title{
СПРОЩЕНА МОДЕЛЬ БЕЗКОНТАКТНОГО ВЕНТИЛЬНОГО ЕЛЕКТРОПРИВОДУ ТА ЙОГО ТЕХНІЧНА РЕАЛІЗАЦІЯ ДЛЯ АВТОНОМНОГО ПЛАВАЛЬНОГО АПАРАТА
}

\author{
Волянська Я. Б. ${ }^{1}$, Онищенко О. А. ${ }^{2}$ \\ 1 - Національний університет кораблебудування імені адмірала Макарова, пр-т Героїв України, 9, Миколаїв, 54000, \\ Україна. \\ 2 - Національний університет «Одеська морська академія», вул. Дідрихсона, 8, Одеса, 65029, Україна. \\ ${ }^{1}$ - ORCID: http://orcid.org/0000-0002-3010-1684 \\ 2 - ORCID: http://orcid.org/0000-0002-3766-3188 \\ e-mail: yanavolyanskaya@gmail.com \\ e-mail: oleganaton@gmail.com
}

Copyright (C) 2017 by author and the journal "Automation technological and business - processes". This work is licensed under the Creative Commons Attribution International License (CC BY). http://creativecommons.org/licenses/by/4.0/

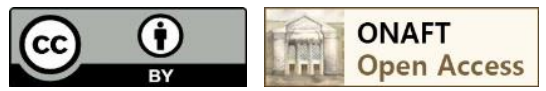

Анотація: Обгрунтовано вибір та показані переваги вентильних безконтактних двигунів постійного струму (БДПС) зі збудженням від високоенергетичних рідкісноземельних постійних магнітів при використанні їх у автоматизованих електроприводах (АЕП) автономних плавальних апаратів (АПА), зокрема, у системах електроруху таких апаратів. Показано, що застосування АЕП на основі БДПС дозволяє розщирити тактико-технічні, експлуатаційні характеристики автономного плавального апарата, збільшити його енергетичні показники, підвищити надійність всієї системи автоматизованого керування електрорушієм. Основні відмінності запропонованого рішення заключні у відмові від використання у АЕП з БДПС дорогого датчика положення ротора (енкодера), проміжного координатного перетворювача, та використанні лише одного датчика загального струму силового інвертора. Створені передумови для технічної реалізації запропонованого рішення дозволяють побудувати декілька альтернативних варіантів принципових схем (технічних рішень) схем АЕП на основі БДПС, з попереднім математичним моделюванням, яке необхідне для налаштування й оптимізації режимів функціонування АЕП у складі автоматизованої системи електроруху АПА. Розроблено спрощену математичну модель запропонованого електроприводу, який функціонує на основі принцииів підпорядкованого регулювання координат. Визначені основні параметри корекиії контурів за відповідними координатами системи електроруху АПА. Створена математична модель дозволила використати принщип мінімальної апаратної надмірності для технічної реалізації схеми управління АЕП з вентильним БДПС. Показана послідовність розрахунку контурів регулювання та використано налаштування на модульний (технічний) оптимум, щзо забезпечує необхідне перерегулювання та час регулювання за всіма координатами системи електроруху. Представлений варіант технічної реалізації та вибору основних елементів системи АЕП оснований на принципі мінімальної апаратної надмірності. Такий принцип побудови АЕП на основі вентильного БДПС для системи електроруху АПА дозволяє зменшити вартість $і$ масогабаритни показники АПА.

Abstract: The advantages and justification of the choice of brushless DC motors with excitation from high-energy rareearth permanent magnets for use in electric drives of autonomous swimming vehicles, in particular, in electric-motion systems, are grounded. Their application allows to expand the tactical, technical, operational characteristics of the autonomous floating vehicle, increase its energy performance, which significantly increases the reliability of the entire system of electric motion. The main differences of the proposed solution are concluding in the following. Do not use an expensive encoder, an intermediate coordinate converter. Only one sensor of the total current of the power inverter is used. The variant of technical realization, the choice of basic elements of the automated electric drive with the minimum hardware obtuse on the basis of the valve brushless DC motor for the system of electric motion of an autonomous floating vehicle is presented. The prerequisites for the technical implementation of the proposed solution are created. This allows to create several alternative variants of principal (technical solutions) of electric drives on the basis of a valve brushless DC motor with previous mathematical modeling, which is necessary for setting up and optimizing the modes of operation of the electric drive in the automated system of electric motion of an autonomous floating vehicle. The sequence of the calculation of the control circuits is shown, the 
setting for the modular or technical optimum, which provides the necessary overregulation and the time of adjustment, is used. A simplified mathematical model of the proposed electric drive, which functions on the basis of the principles of subordinate coordinate regulation, is developed, the main parameters of the correction of the contours according to the corresponding coordinates are determined. The created mathematical model allowed us to use the principle of minimum hardware redundancy for the technical implementation of the circuit of automatic control by a brushless DC motor.

Ключові слова: безконтактний двигун постійного струму, автономний плавальний апарат, електрорух.

Keywords: autonomous swimming device, brushless DC motor, electromotive.

Вентильні безконтактні двигуни постійного струму (БДПС) зі збудженням від високоенергетичних рідкісноземельних постійних магнітів, наприклад, Nd-Fe-B (залізо-неодим-бор), найбільш перспективні 3 усіх типів традиційних електродвигунів для застосування в автоматизованих системах електроруху різних автономних плавальних апаратів (АПА) [1-3]. Використання добавок, що підвищують коерцитивну силу термостабільних магнітів 3 матеріалу $\mathrm{Nd}-\mathrm{Fe}-\mathrm{B}$, у системі збудження БДПС дозволяє зберегти працездатність магнітів при нагріванні до $+170{ }^{\circ} \mathrm{C}$ $[1,2]$ і суттєво покращити експлуатаційні властивості всієї системи управління електрорухом апарата. При застосуванні автоматизованих електроприводів на основі БДПС у АПА проявляється комплекс позитивних конструктивно-технологічних властивостей і техніко-експлуатаційних переваг. Наприклад: відсутність механічних вузлів суттєво підвищує надійність всієї системи електроруху; висока перевантажувальна здатність БДПС забезпечує високу прийомистість АПА; найвищі з усіх двигунів малої потужності енергетичні показники дозволяють підвищити час автономної роботи АПА; забезпечується високий діапазон (1:100 і більше) регулювання частоти обертання гребного гвинта; через низький перегрів у БДПС високий ресурс ізоляції, що дозволяє роботу 3 суттєвими перевантаженнями при маневруванні АПА. Найкращі масогабаритні показники, значний термін служби, високе напрацювання на відмову (понад 104 годин), можливість оптимізації режимів роботи формуванням рівнів обмеження моменту і швидкісних діаграм, також суттєво розширюють тактико-технічні (ТTX) і експлуатаційні характеристики АПА.

Останніми роками вентильні БДПС і електроприводи на їх основі активно виробляються провідними зарубіжними електротехнічними компаніями («Siemens», «General Electric», «Bosch», «Schneider Electric», «Fanuk», ABB та iн.) [4, 5], налагоджується їх дрібносерійне виробництво в Україні (ТОВ «Електротехніка-Нові технології», м. Одеса). Основний стримуючий фактор широкого застосування серійних електроприводів на основі БДПС - ціна перетворювача і наявність дорогого високорозрядного датчика положення ротора (ДПР, в зарубіжних джерелах Shaft Position Sensor aбо Shaft Encoder), наявність розширених сервісно-діагностичних і захисних функцій, ряду інших надлишкових вбудованих систем. Однак для застосування у АПА подвійного призначення ці чинники виявляються несуттєвими, зокрема через те, що є можливості помітного спрощення системи управління [6], застосування найпростіших ДПР [2], відмови від російських матеріалів і комплектуючих.

У [6] представлено функціональну схему електропривода на основі БДПС для АПА. Наведена схема має мінімальну апаратну надмірність і дозволяє створити кілька альтернативних варіантів принципових (технічних рішень) схем електроприводів на основі БДПС з попереднім математичним моделюванням. Таким чином, можна стверджувати, що є передумови для технічної реалізації запропонованого у [6] рішення і $є$ підстави для розробки математичних моделей електроприводу з БДПС, необхідних для налаштування і оптимізації режимів його функціонування у складі автоматизованої системи електроруху АПА.

Метою статті є представлення одного з варіантів технічної реалізації, вибору основних елементів, розрахунку, а також розробки спрощеної математичної моделі автоматизованого електроприводу 3 мінімальної апаратної надмірністю на основі вентильного БДПС для системи електроруху АПА.

Особливості схеми управління вентильним БДПС. На рис. 1 представлено запропоновану структурнофункціональну схему управління частотою обертання вентильного електроприводу, побудовану на основі [6]. Система регулювання швидкості - двоконтурна, 3 підпорядкованим регулюванням координат. Системи 3 підпорядкованим регулюванням координат (СПРК) достатньо теоретично обгрунтовані й апробовані. Використовуємо основну ідею функціонування СПРК, а саме - кожен внутрішній контур підпорядкований задачам регулювання зовнішнього контуру, до якого він входить. Стосовно до двоконтурного вентильного електроприводу (рис. 1), СПРК містить основний контур регулювання швидкості гребного гвинта і внутрішній, підлеглий зовнішньому, контур регулювання струму БДПС.

Контур регулювання струму складається 3: а) релейного регулятора струму, функції якого закладені в нуль-органі HO3; б) модулятора (блок «Розподільник імпульсів - модулятор») і драйверу управління ключами IR2130; в) об'єкту регулювання - трифазного мостового інвертора і силового ланцюга БДПС; г) зворотного зв'язку - датчика струму на резисторі Rs i формувача-підсилювача модуля сигналу (ФМС2).

У контур регулювання швидкості входять: а) регулятор швидкості (РШ) пропорційно-інтегрального типу; б) об'єкт регулювання - замкнутий контур регулювання струму і механічна частина системи електроруху; в) датчик зворотного зв'язку - безконтактний тахогенератор (БТГ) і ДПР [6]. 


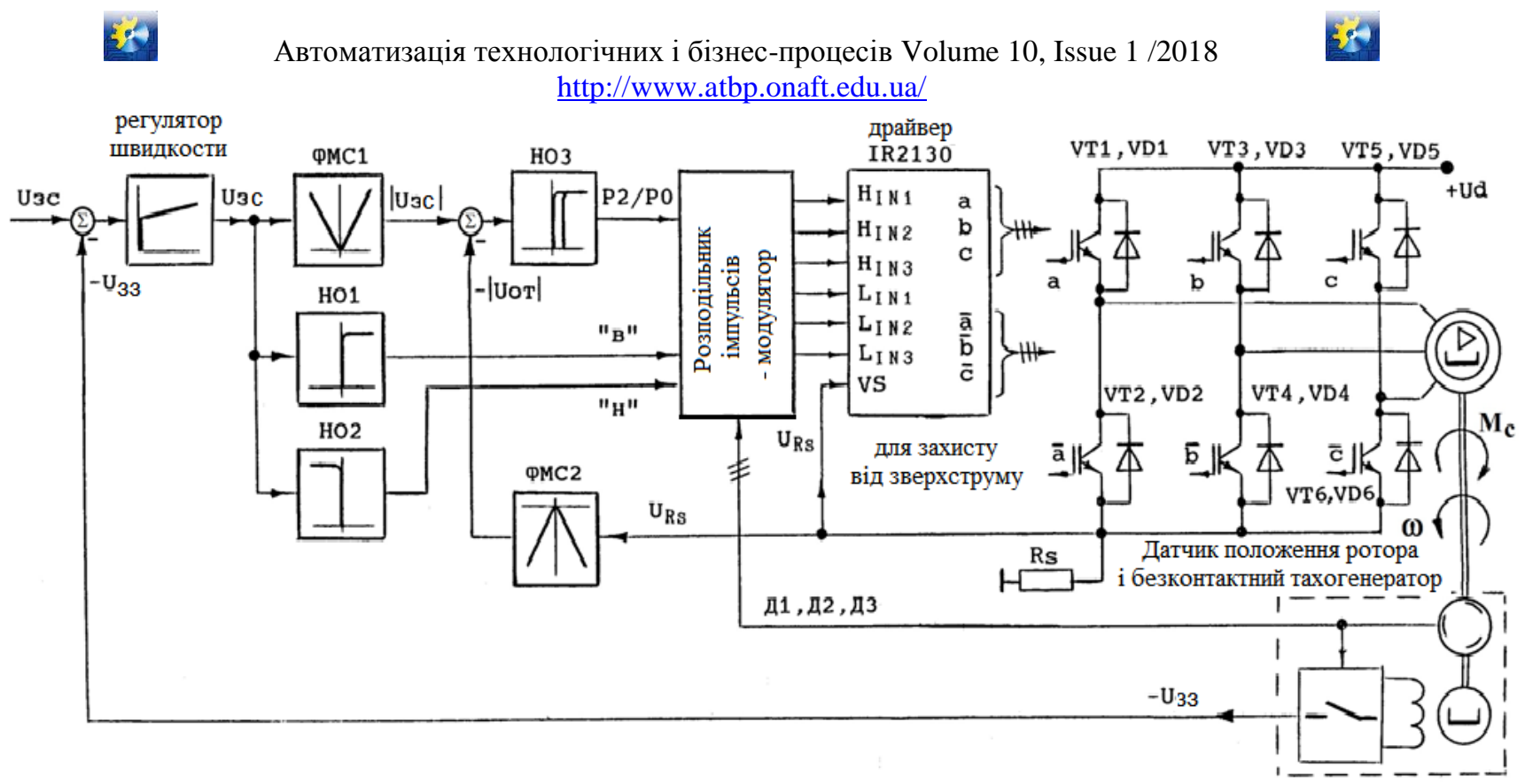

Рис. 1 - Структурно-функціональна схема управління частотою обертання вентильного електроприводу

Спрощена модель вентильного електроприводу на основі БДПС 3 мінімальною апаратною надмірністю. Автоматизований вентильний електропривод являє собою синергетичне об'єднання у складі електромеханічної системи синхронного електричного двигуна зі збудженням від постійних магнітів і електронного комутатора. Оскільки управління ключами мостового інвертора здійснюється за командами ДПР, то таким чином реалізується жорсткий зворотний зв'язок за просторовим положенням ротора, що й визначає алгоритм підключення обмоток БДПС до джерела постійного струму. Щітково-колекторний пристрій, по суті, є механічним комутатором, а його аналог у БДПС - електронний комутатор. Саме ця властивість дозволяє провести аналогію між моделлю вентильного електроприводу на основі БДПС і моделлю класичного щіткового електродвигуна постійного струму, у якого секції обмотки якоря за допомогою щітково-колекторного пристрою підключаються до джерела постійної напруги. Тому найпростіша аналогія між електромеханічним перетворювачем і керованим силовим інвертором складає основну особливість моделювання електропривода 3 вентильним БДПС [6,7]. Для побудови замкнутої системи управління АПА повна модель [6] виявляється надмірною, оскільки враховує всі електромагнітні процеси та процеси перемикання (ДПР, ключів, логічних елементів) що різко обмежує швидкість багатоваріантних (пошукових) розрахунків.

Звернемо увагу на деякі фрагменти моделі, які представляють взаємодію перетворювачів енергії та управляючої інформації. По-перше, збудження від постійних магнітів дозволяє спростити модель еквівалентної обмотки збудження БДПС у порівнянні 3 моделлю синхронної електричної машини 3 електромагнітним збудженням - достатньо представити обмотку збудження як незалежне джерело ЕРС з власним внутрішнім опором. Тоді ЕРС, що наводяться у фазах БДПС, не містимуть складових, пропорційних похідної струму, що протікає у еквівалентній обмотці збудження. По-друге, у моделі вентильного електропривода на основі БДПС легко передбачити можливість зміни частоти обертання у широких межах. Тому обов'язковим є включення до складу моделі механічної підсистеми (наприклад одномасової), що дозволяє визначати миттєву частоту обертання ротора електродвигуна. Передача частоти обертання у допоміжну схему, яка здійснює інтегрування, робить можливим отримання інформації про стан ротора у кожен момент часу (моделювання роботи ДПР). Описане структурне уявлення електропривода, з урахуванням прийнятих припущень і спрощень, дозволяє легко реалізувати засобами MatLab / Simulink його спрощену математичну модель.

Структурна, з елементами принципової схеми, система управління швидкістю вентильного електроприводу наведена на рис. 2. Відзначимо, що налаштування системи починають з внутрішнього контуру, вихідна координата якого (струм якоря) змінюється набагато швидше вихідної координати зовнішнього контуру - швидкості.

Вихідними при налаштуванні є вимоги до статичних і динамічних властивостей контурів і системи: відсутність статичної помилки у сталому режимі при відпрацюванні задавального сигналу, що змінюється стрибком, і перерегулювання, що не перевищує 5 \%. Можливі й інші спеціальні вимоги. Основне призначення контуру струму вентильного електропривода полягає у ефективній стабілізації струму якоря на заданому рівні. У вентильному електроприводі послідовна корекція контуру струму не потрібна, тому що контур струму є практично безінерційним 3 наступних причин.

По-перше, напруга джерела живлення $U_{d}$ набагато перевищує ЕРС самоіндукції двигуна, що дозволяє форсувати процеси наростання і спаду струму $I$ у діапазоні його обмеження (від $-I_{\text {max }}$ до $+I_{\text {max }}$ ) за час, набагато менший сумарної електромагнітної сталої часу $T_{e}$. По-друге, регулятор струму, датчик струму і блок силових ключів конструктивно виконані практично безінерційними. Саме цьому стала часу $T_{e}$ i зворотний зв'язок за ЕРС двигуна практично не впливають на динаміку системи автоматизованого управління електроприводом. 
http://www.atbp.onaft.edu.ua/

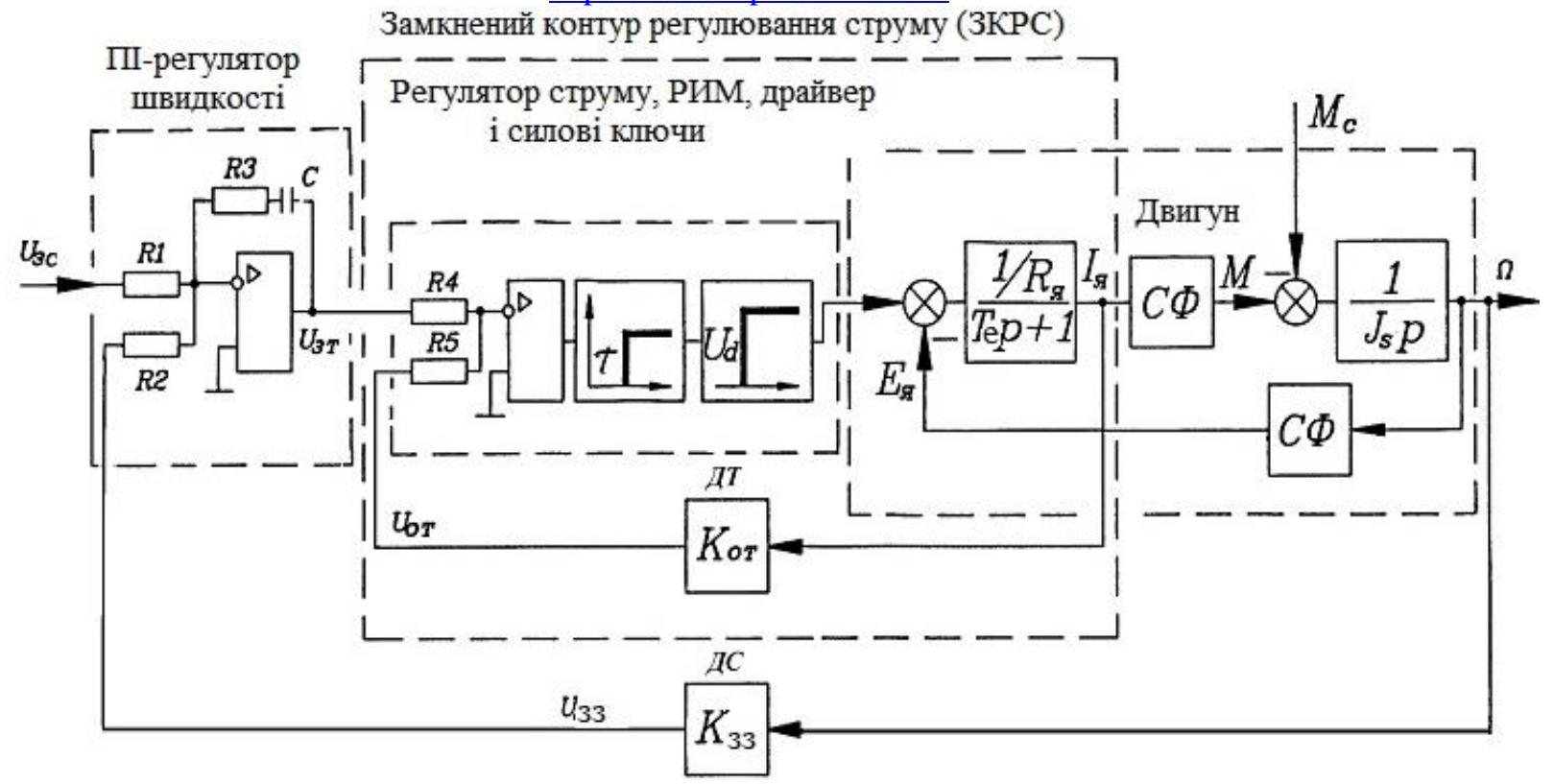

a)

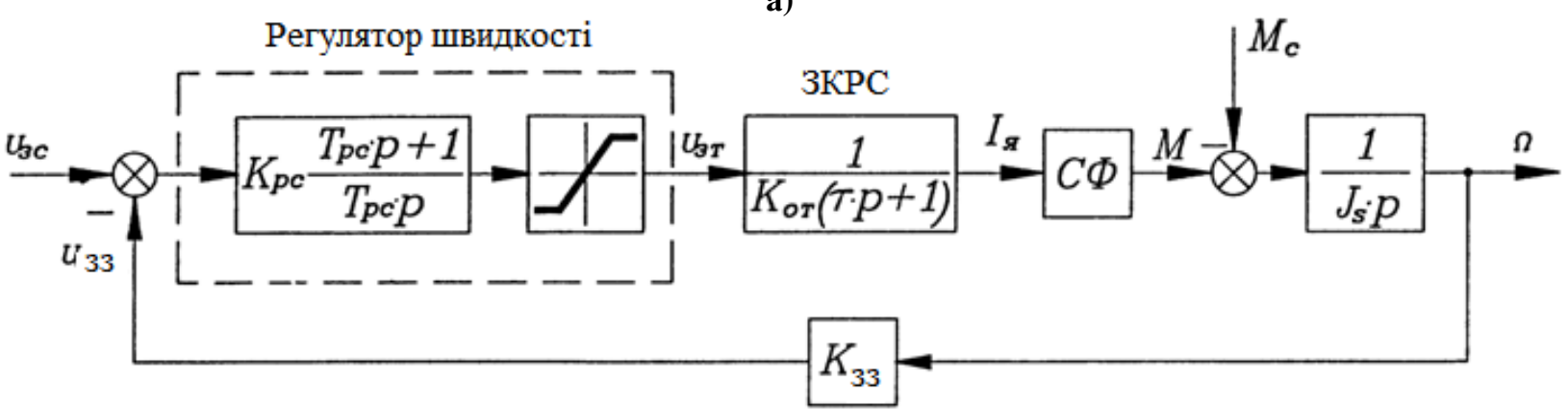

б)

Рис. 2 - Структурна, з елементами принципової схеми, система управління швидкістю вентильного електроприводу

Таким чином, при моделюванні, замкнутий контур регулювання струму наближено представлений аперіодичною ланкою зі сталою часу $\tau=1$ мс і статичним коефіцієнтом передачі ланки $K_{\mathrm{T}}=1 / K_{\text {от }}$. Перетворимо передавальну функцію замкнутого контуру регулювання струму (ЗКРТ):

$$
W(p)=\frac{1}{K_{\text {от }}} \cdot \frac{1}{\tau p+1}=\frac{1}{K_{\text {от }}} \cdot \frac{1 / \tau p}{1+1 / \tau p}
$$

Приймаємо, що «оптимізована» передавальна функція розімкнутого контуру швидкості набуває вигляду

$$
W_{\text {ркс }}(p)=\frac{1}{2 \tau p \cdot(\tau p+1)},
$$

і на частоті зрізу $\omega_{3 p}=0,5 \tau$ ЛАЧХ забезпечує запас за фазою, який дорівнює $63,5^{\circ}$. Тоді передавальна функція «оптимізованої» замкнутої системи описується виразом:

$$
W_{\text {зкс }}(p)=\frac{1}{K_{33}} \cdot \frac{1}{2 \tau p \cdot(\tau p+1)+1} .
$$

Перехідні процеси у такій системі пов'язані з характеристичним рівнянням $2 \tau p \cdot(\tau p+1)+1=0, \mathrm{y}$ якого показник демпфірування $\rho=0,707$. Розглянуте налаштування контуру - налаштування на модульний оптимум, що забезпечує перерегулювання 4,3\% і час регулювання 4,7 $\tau$ Якщо підвищити показник демпфірування, то перехідний процес протікає більш монотонно і час регулювання збільшується. Зі зменшенням показника демпфірування збільшуються коливальність і перерегулювання. Тому, для отримання налаштування на модульний оптимум пропорційна частина регулятора швидкості визначається виразом: 
http://www.atbp.onaft.edu.ua/

$$
W_{\mathrm{p}}(p)=K_{\mathrm{p}}=\frac{K_{\mathrm{oT}} \cdot J_{s}}{K_{33} \cdot c \Phi \cdot 2 \tau}
$$

\section{Висновки}

На основі аналізу властивостей і основних характеристик вентильних БДПС, показано, що вони найбільш ефективні для застосування у автономних плавальних апаратах різного призначення, зокрема, в їх автоматизованих системах електроруху.

Запропоновано:

а) структурно-функціональну схему автоматизованого електроприводу на основі БДПС;

б) простий варіант технічної реалізації електроприводу для системи електроруху АПА на основі БДПС, що використовує принципи підпорядкованого регулювання координат при практично мінімальному числі комплектуючих і елементів;

в) спрощену структурну математичну модель електропривода на основі БДПС, що дозволяє налаштовувати контури струму й швидкості, i, в подальшому, здійснити синтез всієї автоматизованої системи електроруху АПА.

\section{Література}

[1] Волянська Я. Б., Волянський С. М. Особливості побудови автоматичних систем керування рухом об’єктів морської робототехніки // Электротехнические и компьютерные системы. 2016. Вып. 23 (99). С. 39-44.

[2] Карпович О. Я., Онищенко О. А. Особенности реализации датчика обратной связи по скорости и положению в вентильно-индукторном электроприводе // Вестник НТУ «ХПИ». 2003. №. 11. С. 65-70.

[3] Noyal Doss M. A., Vijayakumar S., Mohideen A. J., Kannan K. S., Sairam N. D. B., Karthik K. Reduction in cogging torque and flux per pole in BLDC motor by adapting U-clamped magnetic poles // International Journal of Power Electronics and Drive Systems (IJPEDS). 2017. Vol. 8. no. 1. Pp. 297-304.

[4] Singh S. Kr., Katal N., Modani S. G. Optimization of PID controller for brushless DC motor by using Bio-inspired algorithms // Research Journal of Applied Sciences, Engineering and Technology. 2014. Vol.7. no.7. Pp. 1302-1308.

[5] Srinivasan K., Vijayan S., Paramasivam S., Sundaramoorthi K. Power Quality Analysis of Vienna Rectifier for BLDC Motor Drive Application // International Journal of Power Electronics and Drive System. 2016. Vol.7. no.1. Pp. 7-16.

[6] Volyanska Ya. B., Volyanskiy S. M., Onishchenko O. A. Brushless valve electric drive with minimum equipment excess for autonomous floating vehicle // Electrical Engineering \& Electromechanics. 2017. № 4. Pp. 26-33.

[7] Будашко В. В., Онищенко О. А. Математические основы имитационного моделирования системы управления энергетической установкой бурового судна // Вестник Камчатского государственного. 2014. Вып. 29. С. 6-13.

References

[1] Ya. B. Volyans'ka, S. M. Volyans'kij, “Osoblivosti pobudovi avtomatichnih sistem keruvannya ruhom ob' $€$ ktiv mors'koï robototekhniki” Ehlektrotekhnicheskie i komp'yuternye sistemy, № 23 (99), p. 39-44, 2016.

[2] O. Ya. Karpovich, O. A. Onishchenko, "Osobennosti realizacii datchika obratnoj svyazi po skorosti i polozheniyu v ventil'no-induktornom ehlektroprivode" Vestnik NTU «HPI», № 11, p. 65-70, 2003.

[3] M. A. Noyal Doss, S. Vijayakumar, A. J. Mohideen, K. S. Kannan, N. D. B. Sairam, K.Karthik, "Reduction in cogging torque and flux per pole in BLDC motor by adapting U-clamped magnetic poles" International Journal of Power Electronics and Drive, Systems (IJPEDS)., Vol. 8, no. 1, p. 297-304, 2017.

[4] S. Kr. Singh, N. Katal, S. G. Modani, "Optimization of PID controller for brushless DC motor by using Bio-inspired algorithms" Research Journal of Applied Sciences, Engineering and Technology, Vol.7, no.7, p. 1302-1308, 2014.

[5] K. Srinivasan, S. Vijayan, S. Paramasivam, K. Sundaramoorthi, "Power Quality Analysis of Vienna Rectifier for BLDC Motor Drive Application” International Journal of Power Electronics and Drive System, Vol. 7, no. 1, p. 7-16, 2016.

[6] Ya. B. Volyanska, S. M. Volyanskiy, O. A. Onishchenko, "Brushless valve electric drive with minimum equipment excess for autonomous floating vehicle" Electrical Engineering \& Electromechanics., no 4, p. 26-33, 2017.

[7] V. V. Budashko, O. A. Onishchenko, "Matematicheskie osnovy imitacionnogo modelirovaniya sistemy upravleniya ehnergeticheskoj ustanovkoj burovogo sudna" Vestnik Kamchatskogo gosudarstvennogo tekhnicheskogo universiteta, no 29, p. 6-13, 2014. 